\title{
Gewinnung funktionsfähiger Endothelzellen aus Venen
}

Huber, A ; Bay, U ; Müller-Glauser, W ; Hensel, M-C ; Lehmann, K ; Turina, M

DOI: https://doi.org/10.1515/bmte.1988.33.s2.189

Posted at the Zurich Open Repository and Archive, University of Zurich

ZORA URL: https://doi.org/10.5167/uzh-155060

Journal Article

Published Version

Originally published at:

Huber, A; Bay, U; Müller-Glauser, W; Hensel, M-C; Lehmann, K; Turina, M (2009). Gewinnung funktionsfähiger Endothelzellen aus Venen. Biomedizinische Technik. Biomedical engineering, 33(s2):189-190. DOI: https://doi.org/10.1515/bmte.1988.33.s2.189 


\section{Gewinnung funktionsfähiger Endothelzellen aus Venen}

A. Huber, U. Bay, W. Müller-Glauser*, M.-C. Hensel*, K. Lehmann", M. Turina*

Gebrüder Sulzer AG, Medizinaltechnik, Winterthur

"Klinik für HerzgefäBchirurgie, Universitätsspital Zürich,

\section{EINLEITUNG}

Die Grenze zwischen Blut und Gefässwand wird vom Endothel gebildet. Dieses Gewebe, das aus nur einer schlcht von zellen, den Endothelzellen, besteht, kleidet die Blutgefässe liuckenlos aus. Durch lhre Aktivität verhindern die Endothelzellen, dass das Blut gerinnt. Dagegen verschliessen Blutgerinnsel Prothesen aus alloplastischen Materialien in hohem Prozentsatz, wenn der Innendurchmesser weniger als 6 bis $8 \mathrm{~mm}$ beträgt. Deshalb ist der Ersatz kleiner Arterien bei fehlenden oder unbrauchbaren Venen noch immer eln ungelöstes Problem der Chirurgie.

Um bel kleinlumigen Gefässprothesen eine antithrombogene oberfläche zu erhalten, wird versucht, sie mit autologen, d.h. patienteneigenen Endothelzellen $z u$ versehen $(1,2,5)$. Dafuir werden reine Populationen funktionsfähiger Endothelzellen benötigt. ziel dieser Untersuchung war es, ein Routineverfahren zur enzymatischen Isolation von reinen populationen venöser Endothelzellen zu entwickeln, und die notwendigen Apparate für elne automatisierte Durchführung zu bauen.

\section{METHODE}

Entnahme und Lagerung der Vene

Alle Präparationsschritte erfolgen unter streng aseptischen Bedingungen mit sterilen Instrumenten. Ein Venenstiick wird nach chirurgischen standardmethoden entnommen, mit Kulturmedium (6) gespült und beidseitig kaniiliert. Es wird im Venenhalter (7) montiert ( $\mathrm{Abb}$. 1), so dass es etwa $80 \%$ seiner in situ Länge hat (4). Dann wird der Halter durch einen Glaszylinder gasdicht geschlossen und der Raum zwischen zylinder und vene mit physiologischer salzlösung gefüllt. Das Lumen der Vene wird mit Kulturmedium ausgespült und anschliessend für Transport und Lagerung mit frischem Kulturmedium gefült.

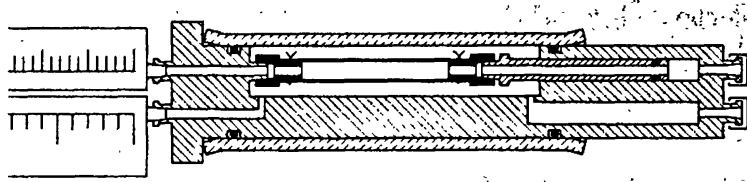

Abb: 1: Venenhalter. Beidseitig kanülierte Vene im Halter montiert; auf der IInken seite spritzen zum spullen und Füllen

\section{Gewinnung der Endothelzelien}

Die Endothelzellen werden mit dem Venenhalter in einem neuentwickelten Apparat $(A b b .2)$ automatisch isoliert. Dem Verfahren liegt eine enzymatische Ablösung der zellen von der Gefässwand zugrunde. Während des ganzen Vorgangs wird darauf geachtet, dass die vene nie kollabiert oder uberdehnt wird. Im folgenden werden die einzelnen Phasen der zellgewinnung kurz beschrieben ( $\mathrm{Abb} .3$ ):

1. Das Kulturmedium wird mit physiologischer Pufferlösung (3) ausgespult.

2. Die Vene wird mit Enzymlösung von $37^{\circ} \mathrm{C}$ gefüllt ( 3 ).

3. Die innere oberfläche der Vene bleibt bei $37^{\circ} \mathrm{C}$.während der Inkubationszeit mit der Enzymlösung in Kontakt.

4. Dabel wird die Enzymlösung in regelmässigen Abständen gegen frische ausgetauscht.

5. Die Vene wird mit Pufferlösung (3) von $4^{\circ} \mathrm{C}$ sanft gespult.

6. Die Vene wird kräftig gespült. Die zellen werden im. Zellabscheidefilter zurückgehalten, während die Enzymlösung mit der, spüllösung durch das filter abfliesst.

7. Die gespülten zellen werden durch eine kräftige strömung mit Kulturmedium von $4^{\circ} \mathrm{C}$ in den vermehrungsreaktor zur. Anzucht transferiert. 


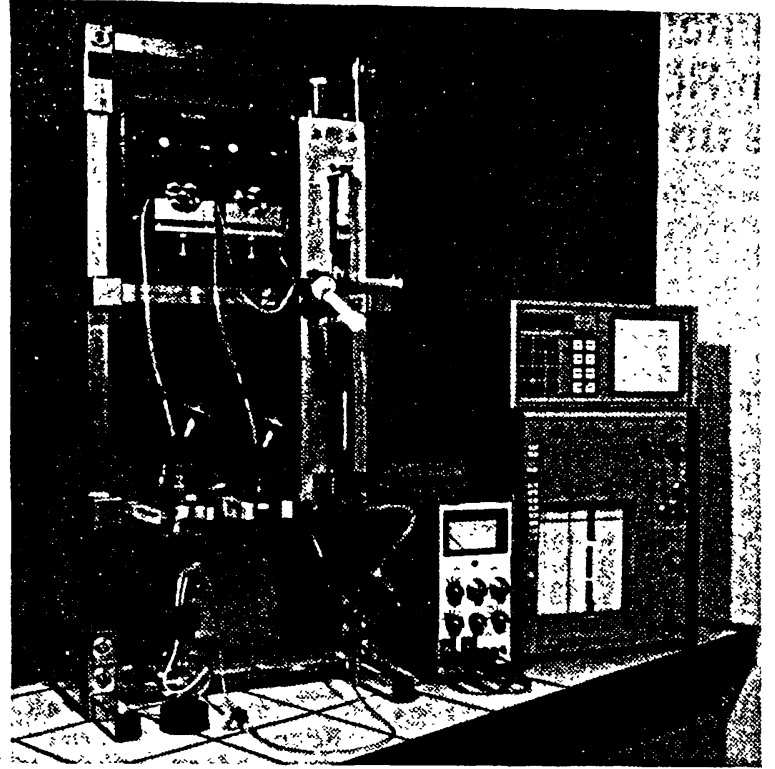

Abb. 2: Automatischer Apparat mit eingesetztem Venenhalter

\section{RESULTATE}

Die Druck- und Flusswerte, die in der Vene während der zellgewinnung auftreten, sind in ihrem zeltlichen verlauf in Abbildung 3 dargestellt. Die Inkubationsphase ist in dieser Darstellung zeitlich stärker gerafft als die übrigen Phasen. Der Druck war nur beim kräftigen Ausspülen der zellen (Phase 6) kurzzeitig leicht hyperton (140 mmHg), d.h. etwas höher als der normale arterielle systolische Blutdruck.

Die Anfärbung (Trypanblau) der Veneninnenseite nach der Isolation zeigte, dass regelmässig über 95 \% der Endothelzellen von der Venenwand abgelöst worden waren. Diese Beobachtung wurde durch rasterelektronenmikroskopische Untersuchungen bestätigt. Die Reinheit der Endothelzellpopulationen wurde an Kulturen durch spezifische Markierung der zellen für das Faktor VIIIrelated Antigen (3) und durch DilAcLDL-Aufnahme (8) nachgewiesen.
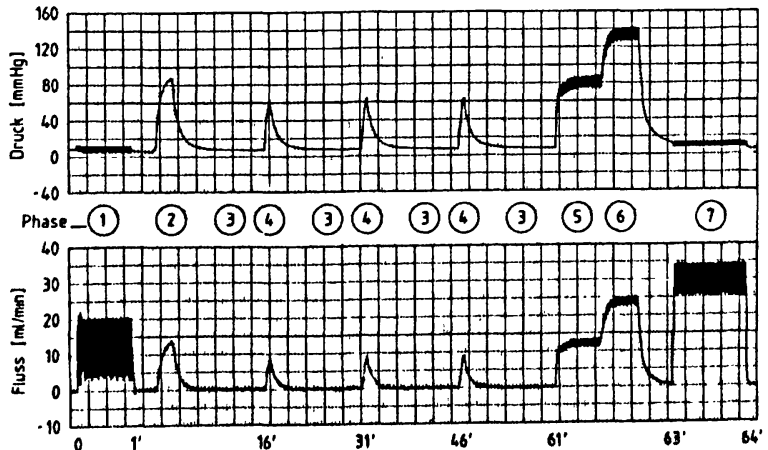

Abb. 3: Druck- und Flussverlauf be 1 elner automatischen Isolation von Endothelzellen aus einer Vene $\mathrm{mit} 4 \mathrm{~mm}$ Innendurchmesser
Die Funktionsfähigkeit der Endothelzellen wurde durch Implantation beschichteter Prothesen in den arteriellen Krelslauf von Hunden gezeigt (5) und auch durch Messung der Prostacyclinproduktion nachgewiesen (5).

\section{DISKUSSION}

Mit den beiden neuen Geräten, dem Venenhalter und der Automatik dazu, die hier beschrleben werden, können reine Populationen von Endothelzellen aus Venen routinemässig gewonnen werden.

Der Venenhalter schützt die Vene während Transport und Lagerung vor Austrocknung und mikrobleller Kontamination. Auch bei der Isolation ermöglicht er eine schonende und definierte Halterung der Vene. Das verhindert Verletzungen der Endothelzellschicht. Es werden darum keine anderen zelltypen als Endothelzellen isoliert, so dass man zellpopulationen erhält, deren Reinheit den Anforderungen für die Prothesenbeschichtung genügt.

Für die Durchführung von grösseren Versuchsserien und vor allem für den späteren klinischen Einsatz ist eine Automatisierung der Endothezellgewinnung unumgänglich. Für diese Anwendungen wurde die Automatik gebaut.

Das neue, automatische Verfahren realisiert sowohl die Qualitätsanforderungen bezüglich Reinheit der Endothelzellpopulationen als auch die Forderung nach effizienter Durchfuhrung der zellgewinnung im Routineeinsatz.

\section{LITERATUR}

(1) Herring $M$, Gardner A, Glover J: · A single-staged technique for seeding vascular grafts with autogenous endothelium. surgery 84: 498-504, 1978 .

(2) Herring $M B$, Compton RS, LeGrand $D R$, Gardner $A L$, Madison DL, Glover JL: Endothelial seeding of polytetrafluoroethylene popliteal bypasses. J Vasc surg 6: $114-118,1987$

(3) Jaffe EA: Culture of human endothelial cells. Transplant Proc 1: No.3, Suppl. 1: 49-53, 1980.

(4) Lehmann $\mathrm{KH}$, Müller-Glauser $\mathrm{W}$, Eay $U$, Turina $M$ : Harvesting of highly purified canine venous endothelial cells for lining of small diameter vascular prostheses. Eur Surg Res 20 Suppl 1: 1, 1983.

(5) Mulller-Gläuser $W$, Lehmann $k H$. Bittmann $P$, Eay $U$, Dittes $P$, von segesser $L$ Turina M: Compliant small-diameter vascular prosthesis lined with functional vencus endothelial cells. Trans Am soc Artif Int organs (in press)

(6) Thornton SC, Mueller SN, Levine EM: Human endothelial cells: use of heparin in cloning and long-term serial cultivation. science 222: 623-625 (1983).

(7) Venenhalter (Patent angemeldet)

(8) Voyta JC, Via DP, Butterfield CE, zetter BR: Identification and isolation of endothelial cells based on their increased uptake of acetylated-low density lipeprotein. J cell B101 99: 2034-2040, 1984. 